\title{
Usefulness of gamma knife pituitary surgery to control thalamic pain after treatment of thalamic malignant lymphoma and report of pathology of gamma knife lesions
}

\author{
Satoshi Utsuki, Hidehiro Oka, Yoshiteru M iyajima, Kiyotaka Fujii \\ Department of Neurosurgery, Kitasato University School of Medicine, Sagamihara, Kanagaw
}

Address for correspondence: Dr. S. Utsuki,

Department of Neurosurgery, Kitasato University School of Medicine, 1 - 15 - 1 Kitasato, Sagamihara, Kanagawa 228-8555 Japan. E-mail: utsuki@ med. kitasato-u.ac.jp

DOI: $10.4103 / 0028-3886.51291$

\begin{abstract}
Abstrad
Here, we describe the first reported autopsy findings following gamma knife surgery for thalamic pain. A 62-year-old man presented with thalamic pain after treatment for thalamic malignant lymphoma. He was treated with narcotic drugs, but his pain was uncontrollable. Treatment using gamma knife surgery on the pituitary gland using a maximum dose of $180 \mathrm{~Gy}$, led to the control of his intractable pain with lower doses of drugs. His death was pain-free and was caused by a recurrence of the tumor, six months after gamma knife surgery. An autopsy was performed and necrosis was present in the area of the pituitary gland where it borders the pituitary stalk. Half of the adenohypophysis was not necrotic, and necrosis was not found in the pituitary stalk.
\end{abstract}

Key words: Gamma knife, intractable pain, thalamic pain, pituitary surgery, adenohypophysis

\section{Introduction}

Thalamic pain occurs after thalamic hemorrhage and infarction, and it is intractable and difficult to control by pharmacotherapy. Levin reported on the usefulness of chemical hypophysectomy for thalamic pain in 1983. ${ }^{[1]}$ Recently, good results for the alleviation of thalamic pain have been reported using gamma knife surgery. ${ }^{[2]}$ Here, we describe the findings from the pathology following gamma knife surgery for thalamic pain that occurred after treatment of a malignant lymphoma of the thalamus.

\section{Case Report}

In July 2004, a 62-year-old man presented with a one-month history of gradually progressing right hemiplegia. Magnetic resonance imaging (MRI) revealed a homogeneous enhanced lesion in the left thalamus and right frontal lobe. He was diagnosed with malignant lymphoma and treated with gamma knife surgery in another hospital. The prescribed doses at the tumor margin and the maximum doses were 16 Gy and 40 Gy for the left thalamic lesion, respectively, and 25Gy and 40 Gy for the right frontal lesion, respectively. The treated lesions reduced in size, but the right hemiplegia did not improve. In September 2004, he was referred to our hospital, since the MRI showed new lesions in the splenium of the corpus callosum and the left frontal lobe [Figure 1]. A total tumor biopsy was performed on the splenium of the corpus callosum on September 24, and histological examination showed a malignant lymphoma. The patient was treated with four courses of intravenously administered methotrexate $(100 \mathrm{mg} / \mathrm{kg})$. After two courses of methotrexate, the enhanced lesion disappeared. In November 2004, the activities associated with his daily life gradually deteriorated because he could not eat in any position other than when lying down and he could not roll over because of the thalamic pain. His pain was not being adequately controlled by his medication, which included 
narcotic drugs. In March 2005, he was given gamma knife surgery to control the thalamic pain. The target was the pituitary gland and the lower part of the pituitary stalk. The maximum dose was 180 Gy and a 100\% isodose line covered the target [Figure 2]. The radiation dose to the optic pathway was kept below a maximum of $10 \mathrm{~Gy}$.

After gamma knife surgery for the thalamic pain, he found it possible to speak, roll over, and he could feed himself when sitting in the upright position, because his pain gradually disappeared. In addition, he could reduce the amount of narcotic drugs taken to control the pain. For some time afterwards he could enjoy his life with his family without unbearable pain. In July 2005, his consciousness gradually declined without unbearable pain and an MRI scan revealed a recurrence of the malignant lymphoma. The MRI scan showed no major changes in the pituitary gland and its periphery after gamma knife surgery. Pituitary hormone stimulation tests revealed normal responses to gonadotropin, thyroid-stimulating hormone, free triiodothyronine, free thyroxine, adrenocorticotropic hormone, cortisol, and growth hormone. Although the thalamic pain was controlled, he had talked to his family before the decline in his consciousness about refusing treatment for the recurrence of the tumor because of his fear about the recurrence of the thalamic pain. His family respected his wishes and they did not request additional treatment. He died on September 21 without any exacerbation of the pain. His family was very comforted that he did not suffer from pain. An autopsy was carried out and malignant lymphoma cells were present throughout the cerebrum. The pituitary gland in the area where it borders the pituitary stalk had become massively necrotic [Figure 3a], but necrosis was not seen in half of the pituitary gland [Figure 3b]. Furthermore, necrosis was not observed in the pituitary stalk [Figure 3c]. Radiation-related necrosis was not found in areas such as the optic nerve and the hypothalamus.

\section{Discussion}

Surgical or chemical hypophysectomy for intractable pain has been performed since the $1950 \mathrm{~s} .{ }^{[3-5]}$ The majority of patients develop significant postoperative complications including panhypopituitarism, severe diabetes insipidus, meningitis, and visual dysfunction. The reason for this may be necrosis in the pituitary stalk, optic nerve, and the pituitary gland, which have been reported from histological observations. ${ }^{[6]}$ Recently, pituitary irradiation using gamma knife surgery has been performed for intractable pain, with good results reported. ${ }^{[7-10]}$ The pain reduction achieved by gamma knife surgery for intractable pain is equal to or greater than that achieved by surgical or chemical hypophysectomy, and few complications arise. ${ }^{[10]}$ There are few cases where gamma knife surgery has been

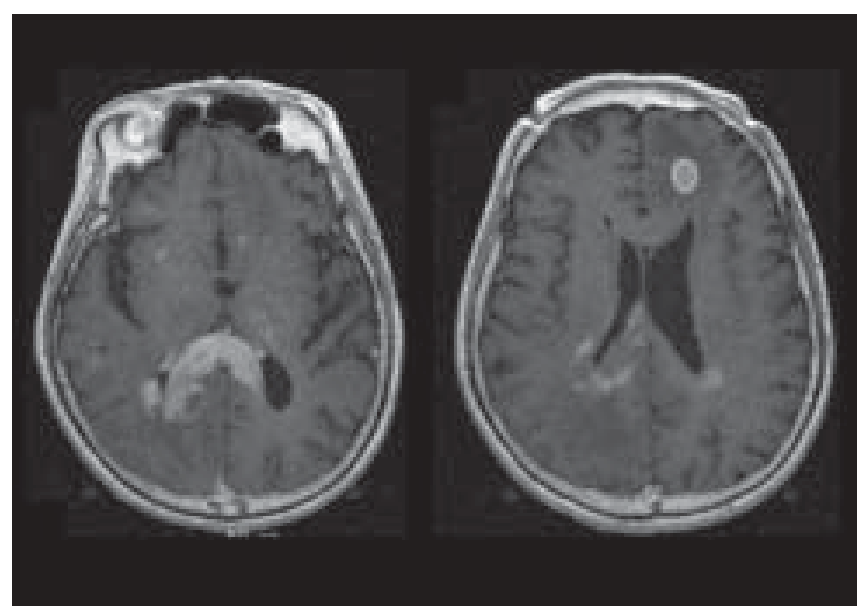

Figure 1: Axial T1-weighted magnetic resonance images with gadolinium revealing homogenously enhanced new lesions in the corpus callosum (Left) and left frontal lobe (Right). There was no mass lesion in the left thalamus

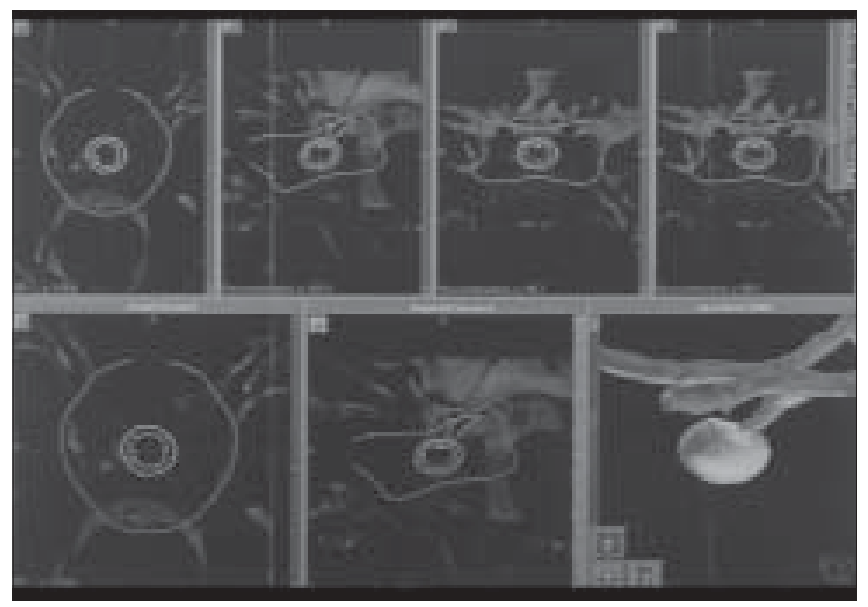

Figure 2: A 3d dose-planning image showing the target, which was within the $100 \%$ isodose line (180Gy) and $10 \mathrm{~Gy}$ isodose line. And it shows the anatomical relationship between the target and the pituitary gland, stalk and optic pathway

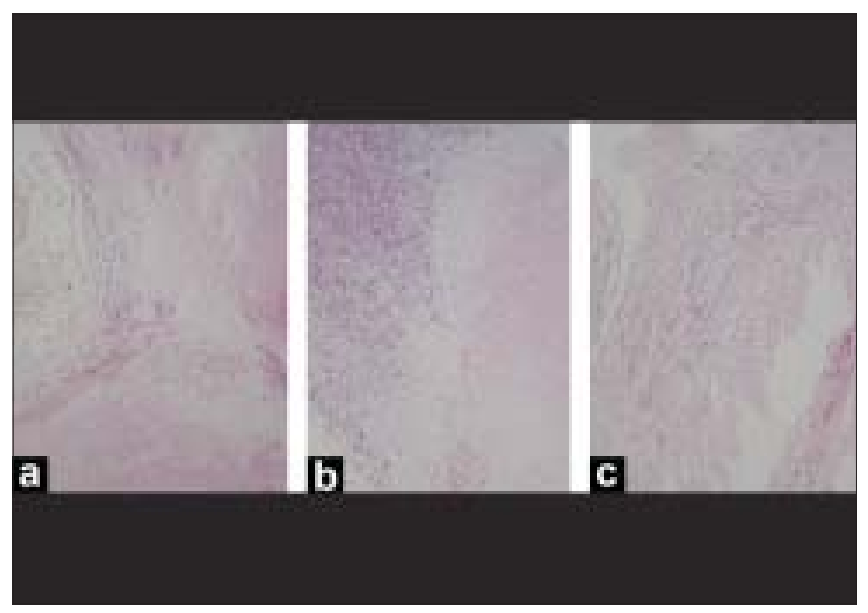

Figure 3: Left: Photomicrograph of the autopsy specimen showing widespread necrosis in the pituitary gland of the pituitary stalk border. Middle: Normal pituitary gland was found adjacent to this necrotic area. Right: There was no necrotic lesion in a pituitary stalk (H \& E, original magnification $\times 100$ ) 
used to alleviate intractable pain, and this problem is further compounded by the short follow-up period. Reports are few, but an initial significant pain reduction of $71 \%$ has been reported, with $21 \%$ of people reporting persistent pain relief for longer than one year when gamma knife surgery was used for thalamic pain. Though $42 \%$ complained of minor complications, there were no severe complications. ${ }^{[2]} \mathrm{A}$ histological study of gamma knife surgery applied to the pituitary gland for intractable pain has not been reported to date. In this study, the adenohypophysis remained partially necrotic after gamma knife surgery to the pituitary gland and there were no histological changes in the optic nerve and hypothalamus, except for a slight change in the pituitary stalk. The few complications associated with gamma knife surgery to the pituitary gland conform with the histological observations in the tissues - that the influence of the gamma knife surgery is confined to the pituitary gland.

There is still no clear explanation for the way that pituitary destruction controls intractable pain. That pain relief was achieved by only the partial destruction of the adenohypophysis as shown in this report, and this may help to elucidate the mechanism of pain relief in the future.

\section{Acknowledgment}

We thank Dr. Motohiro Hayashi of the Department of Neurosurgery, Neurological Institute, Graduate School of Medicine, Institute of Advanced Biomedical Technology and
Science, Tokyo Women's Medical University for the gamma knife surgery planning and treatment.

\section{References}

1. Levin AB, Ramirez LF, Katz J. The use of stereotaxic chemical hypophysectomy in the treatment of thalamic pain syndrome. J Neurosurg 1983;59:1002-6.

2. Hayashi M, Chernov MF, Taira T, Ochiai T, Nakava K, Tamura N, et al. Outcome after pituitary radiosurgery for thalamic pain syndrome. Int J Radiat Oncol Biol Phys 2007;69:852-7.

3. Forrest AP, Blair DW, Brown DA, Stewart HJ, Sandison AT, Harrington RW, et al. Radio-active implantation of the pituitary. Br J Surg 1959;47:61-70.

4. Hardy J. Transsphenoidal hypophysectomy. J Neurosurg 1971;34: $582-94$.

5. Katz J, Levin AB. Treatment of diffuse metastatic cancer pain by instillation of alcohol into the sella turcica. Anesthesiology 1977;46: $115-21$.

6. Takeda F, Uki J, Fujii T, Kitani Y, Fujita T. Pituitary neuroadenolysis to relieve cancer pain-observation of spread of ethanol instilled into the sella turcica and subsequent changes of the hypothalamopituitary axis at autopsy. Neurol Med Chir (Tokyo) 1983;23:50-4.

7. Hayashi M, Taira T, Chernov M, Fukuoka S, Liscak R, Yu CP, et al. Gamma knife surgery for cancer pain-pituitary gland-stalk ablation: A multicenter prospective protocol since 2002. J Neurosurg 2002;97:433-7.

8. Hayashi M, Taira T, Chernov M, Izawa M, Liscak R, Yu CP, et al. Role of pituitary radiosurgery for the management of intractable pain and potential future applications. Stereotact Funct Neurosurg 2003;81:75-83.

9. Liscak R, Vladyka V. Radiosurgical hypophysectomy in painful bone metastases of breast carcinoma. Cas Lek Cesk 1998;137:154-7. Czech.

10. Young RF, Jacques DS, Rand RW, Copcutt BC, Vermeulen SS, Posewitz AE. Technique of stereotactic medial thalamotomy with the Leksell Gamma Knife for treatment of chronic pain. Neurol Res 1995;17:59-65.

Accepted on 06-03-2009

Source of Support: Nil, Conflict of Interest: None declared. 